\title{
The impact of mergers in higher education on micro-level processes - a literature review
}

\author{
Sabine Wollscheid ${ }^{1}$ (D) Trude Røsdal ${ }^{2}$
}

Received: 29 June 2020 / Accepted: 27 August 2021 / Published online: 29 September 2021

(c) The Author(s) 2021

\begin{abstract}
Amidst increased research on mergers in higher education, studies addressing micro level processes are scarce and fragmented across disciplines: our aim is to systematically review existing studies, providing implications for research and practice. We grouped 21 studies from different countries under four themes: academic identity and self-image; cultural integration; staff reaction; teaching and research. Timing, status of institutions and staff, and disciplinary cultures apparently affect post-merger micro-level processes. Policy reforms might indirectly address micro-level processes following a merger, for example in a change of academic identities. Few studies investigated the impact of mergers on teaching and research activities. Studying merger consequences for academic core activities is complex, requiring a longer perspective involving students, staff and quantitative indicators. Longitudinal design in further studies might investigate changes from different angles and for different staff groups and students, exploring country differences in micro-level processes, applying a comparative design. Despite limitations, our review might inform the planning of merger processes regarding reactions at micro level.
\end{abstract}

Keywords Mergers of higher education institutions $\cdot$ Micro level processes $\cdot$ Systematic review $\cdot$ Cultural perspective $\cdot$ Academic identity perspective $\cdot$ Emotional perspective

\section{Introduction}

Mergers in higher education have been primarily motivated by arguments of efficiency (e.g., Harman \& Harman, 2003) and quality enhancement (e.g., Frølich et al., 2016) related to academic standards (e.g., Damşa et al., 2015). Most studies address factors related to merger decisions at the meso level, including efficiency (e.g., Johnes \& Tsionas, 2019), research productivity (e.g., Liu et al., 2018), in addition to branding, leadership and management (e.g., Harman \& Harman, 2003; Skodvin, 1999).

Sabine Wollscheid

sabine.wollscheid@nifu.no

1 Nordic Institute for Studies in Innovation, Research and Education (NIFU), Økernveien 9, Tøyen 0653, Norway

2 University of South-Eastern Norway, Grønland 58, Drammen 3045, Norway 
In contrast, research at the micro level, comprising small scale phenomena in result of a merger decision (see e.g., Ylijoki, 2014) is relatively scarce and fragmented. At the same time, research of micro level processes is important, as it addresses those individuals who are directly affected by the mergers, such as academic and administrative staff. Addressing this gap, our aim is to identify and review this literature to provide a more consistent picture of that knowledge. We agree with Harman and Harman (2003) that sensitivity to human and cultural factors is crucial for successful mergers. By micro-level processes we mean activities and routines related to staff (academic and administrative), changes in (academic) identities, and staff emotions and perceptions.

Our review is motivated by the argument that that mergers indirectly affect teaching and research by changed activities and routines at the micro level in result of a merger decision. For example, academics, who are moved from a more teaching-oriented to a more research-oriented institution, might reduce their effort in teaching by spending more time on research.

Higher education institutions, here, comprise universities, university colleges (colleges of applied sciences) and research institutions. ${ }^{1}$ They can be labeled 'hybrid', assumed to employ different cultures (academic vs. administrative) and disciplines (Becher \& Trowler, 1989). Mergers might enhance complexity, as different institutions might have distinct sectoral roles. Universities and university colleges, for example, vary in their academic role, their focus on teaching vs. research, their organizational culture (Harman, 1989), and their reward structure (Harman, 2002).

Describing different types of mergers Harman and Harman (2003) distinguish first, between voluntary mergers, resulting from the initiative of the participating institutions themselves, in contrast to forced mergers, for example initiated by the government; second, between horizontal mergers, that is mergers of institutions that provide courses in the same field of study, and vertical mergers, offering courses in different areas. Third, they distinguish between consolidation of two or more institutions of similar size forming a new institution, and the 'take-over' of a small institution by a large institution. Fourth, mergers can involve institutions from one higher education sector (single sector), or they might involve institutions from different sectors. Finally, one can distinguish between two-partner and multi-partner mergers. Acquisition mergers of different-size institutions and complementarity mergers have been shown as more successful than consolidation mergers (e.g., Boling et al., 2017) and voluntary mergers turned out to be more successful than forced (e.g., Skodvin, 1999).

In the following, we focus on the categorization voluntary vs. forced and horizontal vs. vertical, in addition to number of institutions involved in a merger. We assume that these categories are most frequently used in the literature on mergers of higher education institutions. By focusing on few categories, we aim to reduce complexity in our analyses.

\footnotetext{
1 The term higher education institution is well established in the literature and will be used consistently. The term organization, however, will be used when speaking of organizations, in general.
} 


\section{Overview of the literature}

Some scholars in different disciplines have studied changes at the micro level, in consequence of a merger. By exploring how academics respond to structural reforms in a Finnish context, and how these mechanisms shape academic culture, work practices and academic identities, Ylijoki (2014) found that the most common construction was that of a 'conformist identity', referring to academics who adapt to structural change, in contrast to a 'resistant identity'. The 'dramaturgical identity' draws on reflexive impression management, showing a kind of façade to create a proper image. However, because of the complexity of interrelated changes, Ylijoki (2014) seemed to be unable to separate impacts of the reform, but concludes that structural reforms seemed to have both intended and unintended effects, as they influence the working climate and sensitize academics to an increasing need for profiling, branding and justifying their existence.

Addressing differences between academic and administrative staff, Safavi and Håkanson (2018) found that the merger of a large, research-intensive and international recognized university and a smaller, well-acknowledged art college in the UK, was perceived very differently by administrative and academic staff. Teaching and research seemed to be weakly affected by the merger, as these activities were undertaken in discipline-based departments with different profiles. In both institutions, high quality of teaching and research was recognized. For most academics, the merger notably meant only small changes to ongoing activities, mainly related to the unique academic culture of the art college, its quality of research and small overlap between its teaching and research with those of the larger research-oriented university. In general, academic staff could go on with teaching as before, and those engaged in research continued without disruption. According to the study authors, one should regard these findings in their context, with two institutions with a long history of collaboration, the backdrop for this voluntary merger. This might partly explain behavior and lack of resistance of the academic staff. In contrast, for administrative staff in the art college, the merger led to major changes and was perceived as a threat to careers and job security.

For the integration of a national educational research institute into a Grande École in France, Evans (2017) found that faculty of the research institute evaluated their environment as less congenial and satisfying than colleagues of the larger institution. In general, findings showed widespread dissatisfaction, lowered morale, frustration and disillusionment created by people's impeded possibility to carry out their work as they wished.

Following a horizontal forced merger between two departments within the same university in Australia, Dasborough et al. (2015) investigated how employees' perceptions shape emotional responses toward organizational change and explored emotional variation. They found that at the anticipation stage, people can be categorized into three qualitatively different understandings, determined by their perception of the upcoming change and their emotions attached. These were either a promising, a threatening or an inevitable understanding. The promising understanding was solely held by older males and full professors with tenure; the latter were mainly held by those who were younger and untenured. Further, it was shown that emotions became less intense over time, moving from anticipatory emotions of hope and fear, to realized emotions of happiness and sorrow.

Furthermore, Lawlor (2013) followed a so-called horizontal micro-merger of two halves of the same faculty of an Irish higher education institution, investigating the post-merger impact. The one half of the merging faculty had to physically move their workplace from one building to another, which improved work environment and overall satisfaction among 
staff. But although a 'happy' merger, it also resulted in feelings of uncertainty related to job security.

These studies address different issues in relation to a merger at the micro level such as changing academic identities, changing academic cultures, differences in perception across different staff groups and strong feelings associated with the merger. Mergers in higher education have been studied from different perspectives (Ripoll-Soler \& de-MiguelMolina, 2019), but at the same time existing studies are highly diverse, applying different theoretical perspectives, and are fragmented, i.e., published in different journals. There exists no synthesis of this body of knowledge addressing the micro level at higher education institutions.

Thus, given the lack of a systematic review on this knowledge, our aim is to systematically identify, map and synthesize studies, to configure a more complete picture. We aim to identify studies additional to those above, addressing the micro level in result of a merger decision and to describe implications for further research.

\section{Review question and assumptions}

Studies on mergers in higher education can be characterized by qualitative designs with limited generalizability (e.g., Aagaard et al., 2016; Evans, 2017; Harman \& Harman, 2008; Safavi \& Håkanson, 2018). Limiting the scope to micro-level processes, we expected to find few studies to investigate processes at the micro level comprising academic and administrative staff. Thus, we exclude students as they are affected by the merger at a larger distance.

Given different type of mergers in higher education we ask the following review question: Does type of higher education merger affect micro-level processes? Drawing on the review above, we assume that merger types impact phenomena on the micro level such as changes in academic identity, staff integration, a variety of staff emotions and the core activities, teaching and research. We suppose that micro-level processes might differ for academic and administrative staff groups.

Further, we assume that the national context including educational policies at the macro level, in addition to the type of merger, has an indirect impact on the micro level. Comparing performance outcomes of successful mergers of high-performing universities in a European context, Ripoll-Soler and de-Miguel-Molina (2019) found a mix of different factors at local, national and international level that needed to be analyzed in the integration phase, before a merger could be regarded as successful.

\section{Method}

Our method is informed by a meta-synthesis approach, a type of qualitative evidence synthesis. Considering potential relationships of themes across single studies, this approach focuses on findings across studies that are both in conflict and complementary (Walsh and Downe 2005; cit. in Saini and Shlonsky, 2012). The aim is to keep the original meaning of each primary study (Walsh and Downe 2005), while critically analyzing findings between studies for congruencies and similarities (see, Thorne et al., 2004). Characteristics of a qualitative evidence synthesis are the extraction of themes, their comparison and contrast, and the synthesis of findings. This approach starts with a predefined research question and assumptions guided by previous research - as presented in the previous section - and 
followed by strategies for systematic literature search, study selection, data analysis and synthesis of findings (see, Thorne et al., 2004).

\section{Literature search and study selection}

We limited our search to empirical studies published in English in peer-reviewed journals from 1999 to 2020. We conducted a search in the following electronic databases: WoS (Web of Sciences) and ERIC (Education Resource Information Center), in addition to Google Scholar. Key terms were merger, higher education, university, college, culture, micro and staff. For each database, these terms were truncated and combined by using BOOLEAN operators AND and OR.

We conducted the literature search in April 2018 (updated in March 2020) in collaboration with our research librarian. To retrieve qualitative studies is challenging, as they are less well indexed in electronic databases. To identify additional studies, we combined the search in databases with snowball searches in reference lists of core articles. Further, we conducted hand searches in two leading journals in the field, Studies in Higher Education and Higher Education, and in a book series published by Springer (Higher Education Dynamics); we particularly investigated Volume 46, Mergers in Higher Education. The search resulted in approximately 750 articles in total.

We screened titles and abstracts and ended up with approximately 70 articles. These were retrieved in full text and read according to the following inclusion criteria: first, it had to deal with a merger of higher education institutions; second, it had to address microlevel processes addressing staff at different levels; third, it had to be an empirical study; and fourth, it had to be published in a peer-reviewed journal or book series addressing the topic.

Of the approximately 70 full-text articles, we excluded 49 studies after full text reading. These were excluded mostly because they did not address the review question on micro level perspectives related to mergers in higher education, and for example rather dealt exclusively with structural changes (Kyvik, 2004), reorganization (Yang, 2000), organizational change in higher education (Gornitzka, 1999), power relations (Marginson, 1997) or other aspects, not addressing micro -level processes, for example academic productivity on an aggregated level (Liu et al., 2018). A few articles were also excluded, as they were no empirical studies (Elliot, 2005; Rowley, 1997). We ended up with 21 eligible studies for analysis. These were exclusively published in international journals, and most of them were categorized as vertical forced mergers.

\section{Coding and analysis}

The analyses includes a map of studies according to the following characteristics: author and publication year; country; merger types/categories, according to Harman and Harman (2003) (if reported), in addition to name and number of higher education institutions involved (if reported); aim of the study (in relation to the review question); study design; main findings/conclusions provided by the study author(s). Data were collected in an Excel-sheet template specified for the purpose of our review. Such a mapping approach can be characterized as a descriptive analysis, inspired by document and content analysis techniques (e.g., Robson \& McCartan, 2011), consisting of several tasks, which are iterative rather than subsequent. 
We read the included studies, and we applied a wide reading strategy to screen titles and abstracts and capture basic information on authors, publication year and publication channel and country context. During narrow reading, i.e., a re-reading of specific parts (e.g., introduction, method, findings and conclusions), we coded corresponding text with respect to the review question. During this process core findings and conclusions provided by the study author(s) were read with the lens of our review questions (Robson and McCartan 2011). Informed by a meta-synthesis approach, we coded main phrases and themes across study findings. The analysis was supported by means of the computer-assisted qualitative data analysis software (CAQDAS) NVivo to facilitate data management and increase transparency and rigor (Richards, 2009). The coding process was informed by our assumptions, and careful reading of the included studies. Thus, the coding process, can be characterized as both deductive and inductive. Most of our data, i.e., included studies drawing on qualitative epistemology. For studies drawing on quantitative epistemology we used the authors' conclusions, rather than statistical findings for our synthesis. To increase taxonomic validity and ensure reaching thematic saturation, the first author coded the included studies which provided a provisional coding taxonomy, which was validated and revised by the second author. The final structure of codes was developed in dialogue between the first and second author.

\section{Findings}

In the following we provide a mapping of the included studies, which is then followed by a synthesis of core themes within and across the studies.

\section{Study description}

We included 21 studies in our review, published between 2004 and 2019. Among these, four studies were conducted in South Africa, four in the United States and five in Finland. Three were conducted in the United Kingdom (including Northern Ireland) and one in Ireland. The remaining studies were conducted in Australia (1 study), China (1 study), Denmark ( 1 study) and France (1 study). Limiting our sample to English language, this picture might have some language bias. We nevertheless assume that the relevant studies in the field are published in English. In most of the studies, the mergers can be classified as vertical forced mergers of two or more higher education institutions; three can be described as horizontal forced, and one as a vertical voluntary merger. Most studies applied a qualitative design, of which most applied a case study design, including different data sources. The remaining quantitative studies applied either a survey among staff members, a bibliometric design in combination with a survey, or a longitudinal design including a survey before and after the merger.

Table 1 describes the sample of included studies according to merger type and institutions, study design and study aim addressing our review question. Our categorization of mergers was mostly drawn from information given by the study authors (Fig. 1). 


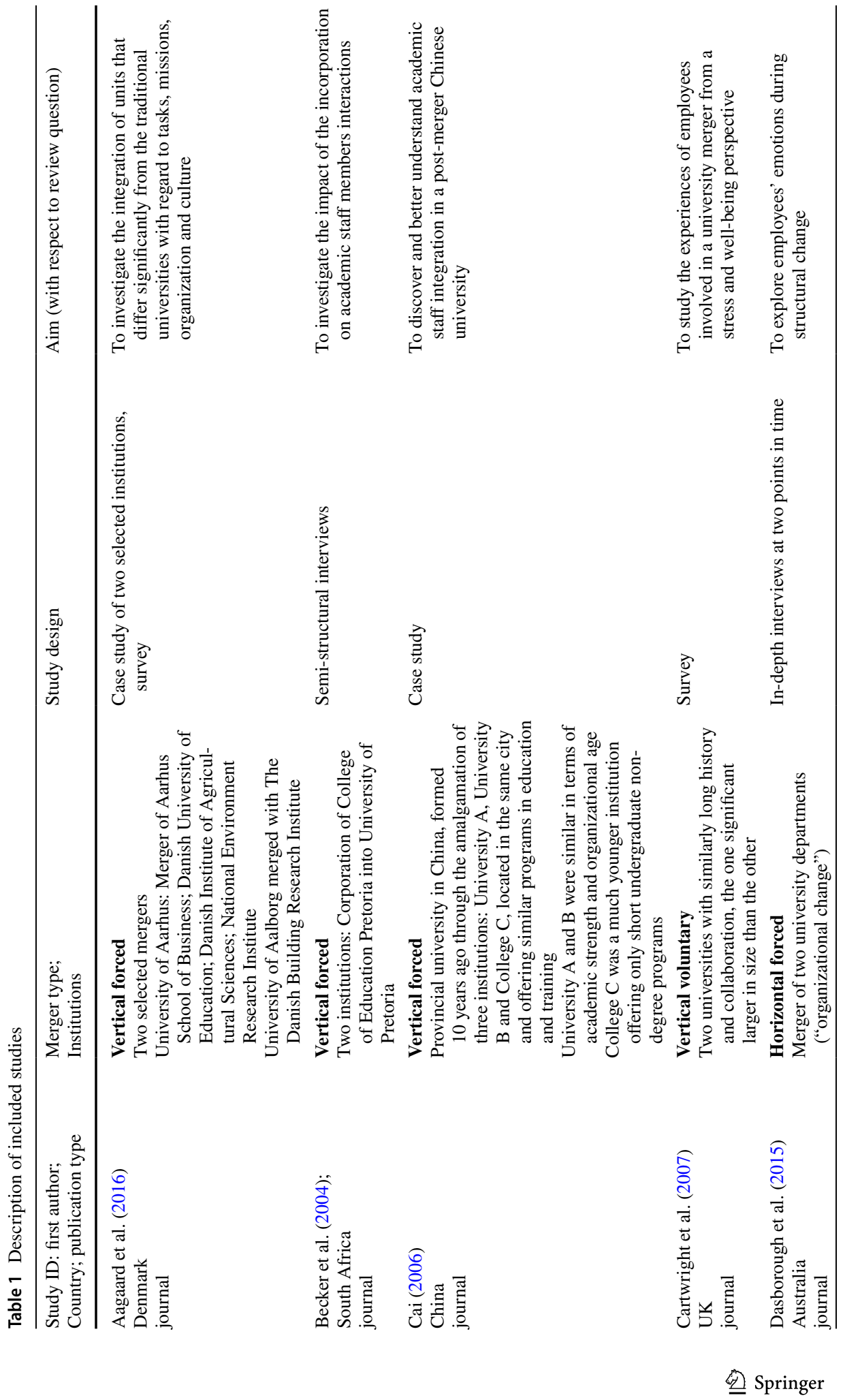




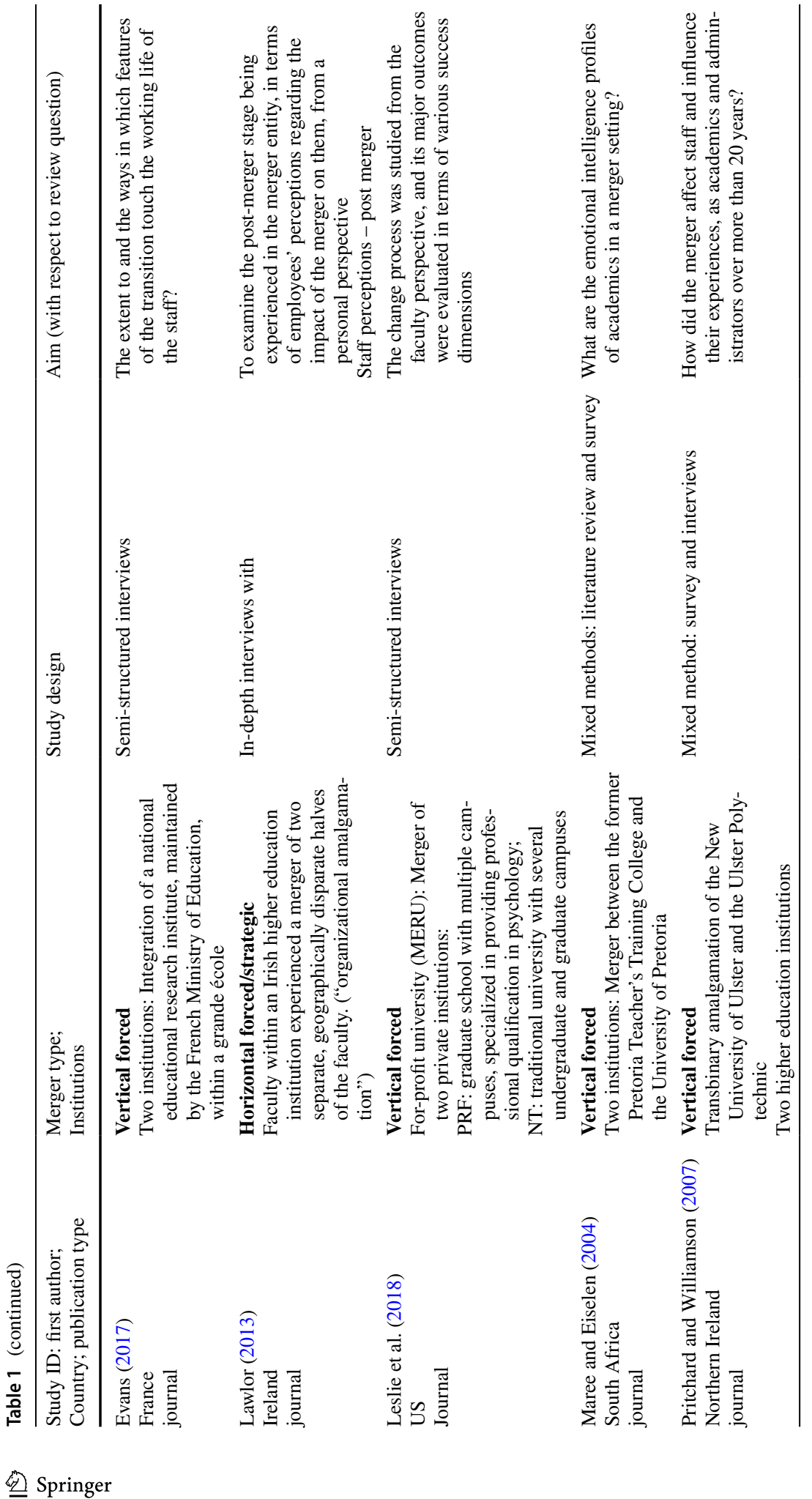




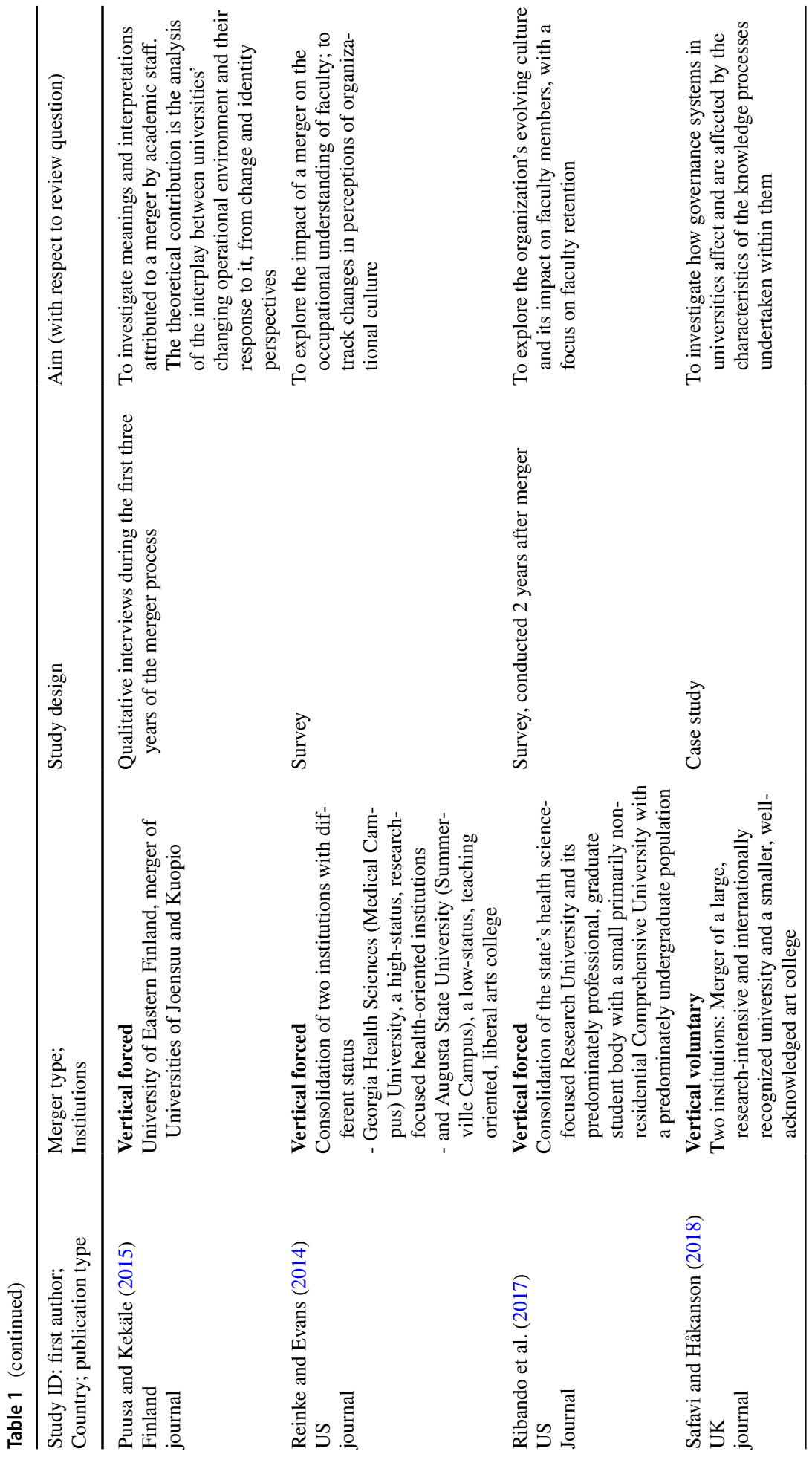




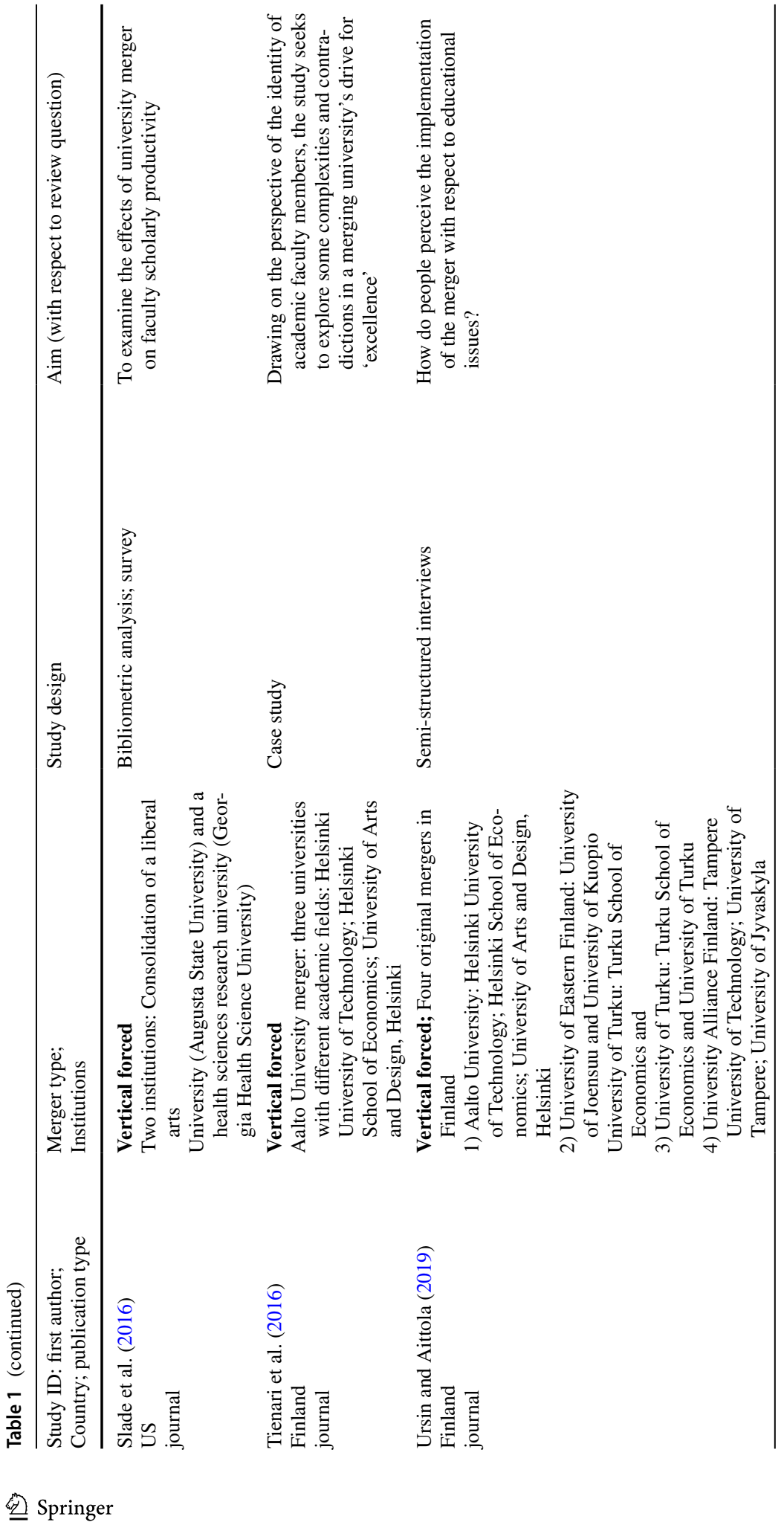




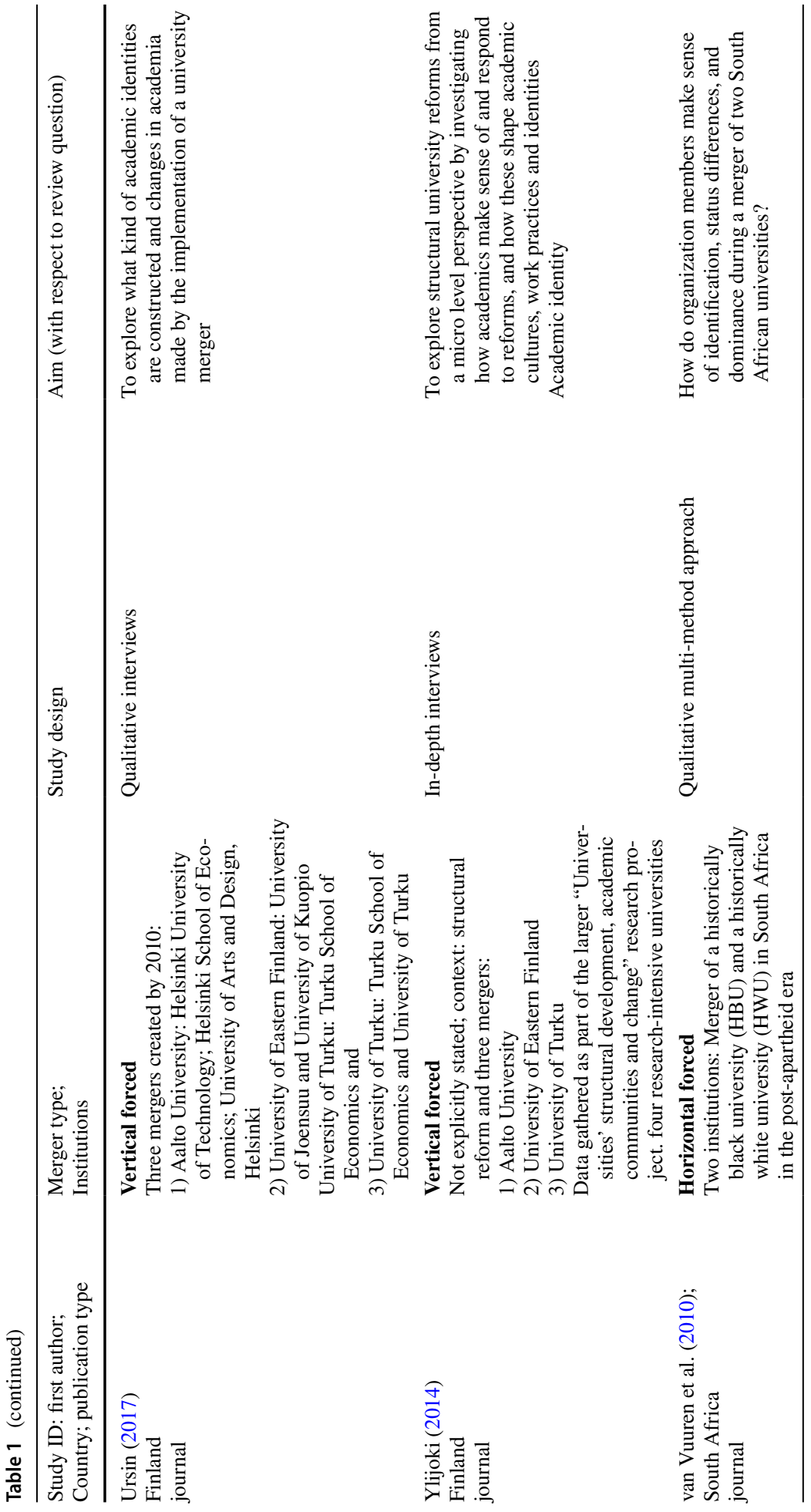




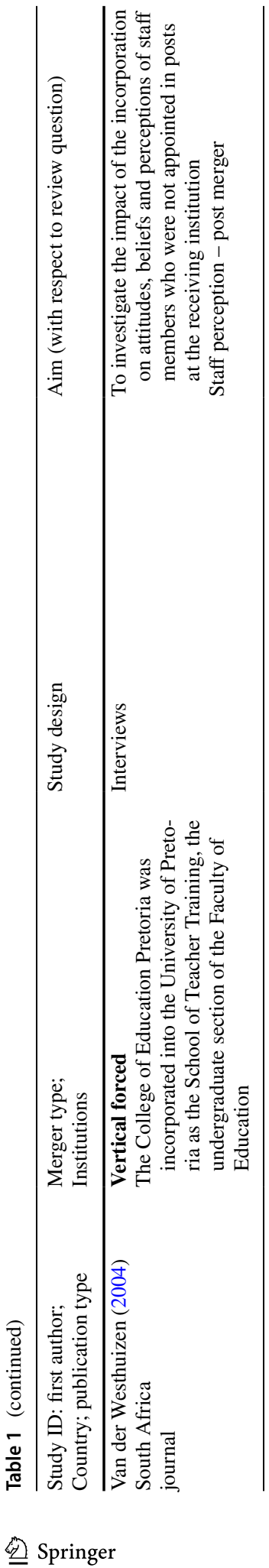




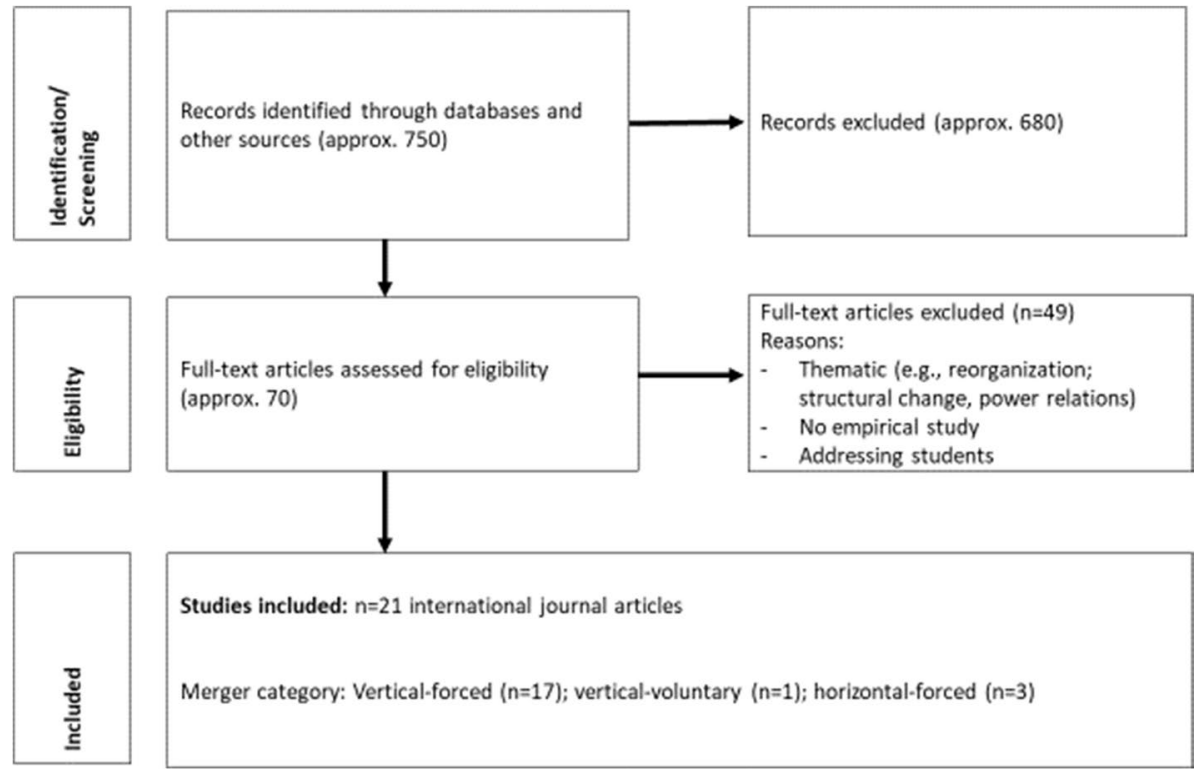

Fig. 1 Flow diagram - data collection

Micro level processes according to merger decisions

time

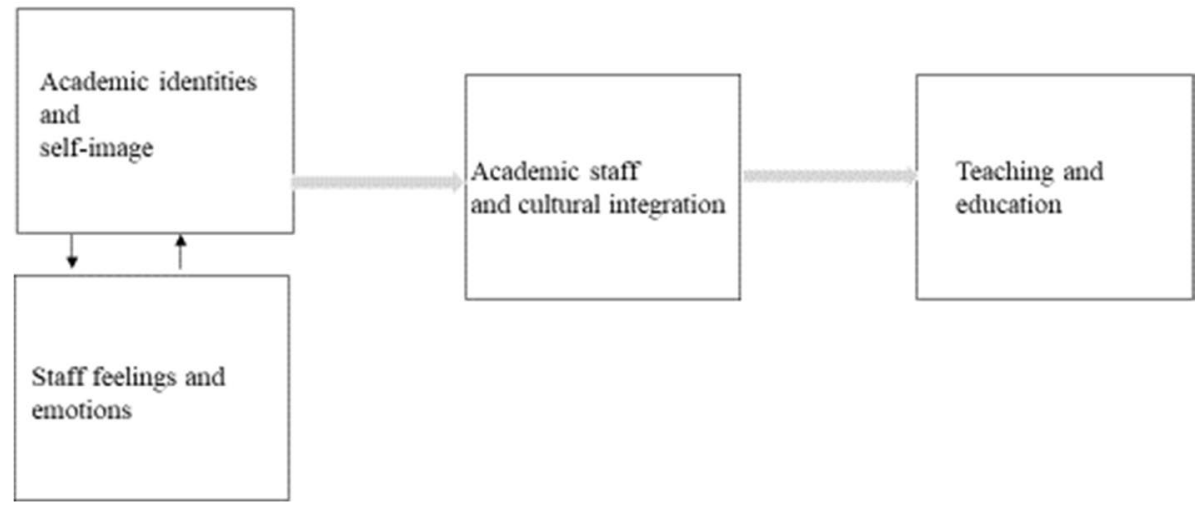

Fig. 2 Themes at the micro level linked to a merger decision

\section{Thematic synthesis of studies}

In our analysis, we generated four main themes at the micro level, each including several sub-themes or codes: 1) academic identity and self-image; 2) academic staff integration and cultural integration; 3 ) staff feelings and emotions; 4) teaching and research. Figure 2 
presents the four themes in relation to each other. While academic identities and selfimage, and staff feelings and emotions are linked to the individual staff members from the beginning of the merger decision, academic staff integration and cultural integration as well as teaching and research can be related to later processes of the merger at the micro level, with a focus on staff at the merged institution.

\section{Academic identity and self-image}

One core theme we identified in several studies was that of academic identity and selfimage, and changes related to these self-perceptions associated with the merger decision and merger process. In the Finnish context, institutional mergers have created larger units, which have transformed the external conditions for academics and their work. According to Ursin $(2017,314)$ 'structural and organisational changes inevitably have impact on how academics perceive their roles and places in academia [i.e., their academic identity]'. Several studies stress an ambiguous impact on academic identities, illustrated by the following quote: 'the impact of the incorporation on the self-image and professional identities of the [...] staff yielded decidedly mixed results.' (Becker et al., 2004, 160). For a vertical forced merger, the corporation of two colleges in South Africa, among college staff members Becker et al. (2004) identified perceptions of inadequacy on the one side, and of assertiveness, on the other side. They conclude that the incorporation 'led to some very deep soul searching and personal evaluations about College staff members' own abilities and even their self-image' (160).

For vertical forced mergers of three institutions in Finland, Ylijoki (2014) identified three different conceptions of academic identities: The conformist identity refers to academics that adapt to structural change, turning out to be the most common identity in the study. In contrast, the dramaturgical identity implies reflexive impression management, in which academics aim to create a proper image of themselves. Finally, the resistant identity indicates obvious opposition and protest towards structural reforms. Drawing on the same cases, also Ursin (2017) elaborated stories of conflicting academic identities representing both regressive and progressive narratives. In the regressive narrative changes are perceived negatively, as it reflects the vanishment of one's work context and one's standing in the academic community. In this narrative, changes in higher education are forcefully opposed for moral and ethical reasons, as these are often associated with management and neo-liberal ideologies. In the progressive narrative, however, structural changes such as mergers in higher education are perceived positively reflecting improvement and progress. In this respect, Ursin (2017) concludes that these findings for Finnish academic identities are in line with the development of European higher education institutions, towards a more dynamic and hybrid understanding of an academic in the twenty-first century, compared with the traditional understanding of a more static academic identity. From this perspective, academics like other professional groups might adapt more flexibly to structural changes at the micro level.

Tienari et al. (2016) studied the case of the Aalto University, a merger of three universities in Finland, each with different fields of study. Considering how complexities and contradictions of the merger were reflected in academic identities of faculty members, they found two conflicting rationales, an 'increasing emphasis on basic research in disciplines' (35) during the merger process on the one side, and a stronger focus on interdisciplinarity, innovativeness and practical applicability, 'woven into the very fabric of the merger' (35) on the other. An important point is that unifying different groups of people in a 'new' 
institution takes time, particularly true for university mergers, 'where people tend to identify with the work they do, rather than with the university as a whole [...]' (36). Another topic the authors raise is that of a 'polarization' of academic identities among staff, as a result of a new human resource system by the new institution, which might lead to a clear stratification between different groups of academics. A further stratification between staff members in results of a merger decision was a topic in several studies.

Becker et al. (2004) investigated the impact of an incorporation of one college and a university in South Africa on the interaction of staff members. They identified one group of college staff members, who felt that their self-worth and self-image was diminished. In contrast, those who were selected for a position at the incorporated institution expressed positive feelings related to their academic identity. Thus, this finding is in line with a point by Tienari, Aula and Aarrevaara that in the case of university mergers the way 'how people identify [...] with the merged organization [and further, academic identity] is intrinsically associated with the perceived stratification of faculty members $(2016,36)$.'

Studying a vertical voluntary merger of a large, research-intensive and internationallyrecognized university and a smaller, well-acknowledged art college, Safavi and Håkanson (2018), however, has found a 'preservation' integration strategy matching employees' wish to maintain their autonomy and identity.

In sum, the studies above illustrate that the impact of mergers in higher education on academic identities and self-images is highly complex and highly ambiguous. They reveal contrasting academic identities, such as conformist academic identities with progressive narratives on the one side and resistant identity with regressive narratives on the other side. How this mechanism and pattern unfold might be related to institutional status, stratification across disciplines and, at the individual level, the professional status of the academic.

\section{Academic staff integration and cultural integration}

Academic staff and cultural integration into the new institution is a theme that is closely related to that of academic identities. Studying a post-merger process of vertical forced merger in China, Cai (2006) found that the new identity of the organization would change staff members' way of thinking and their behavior, in the case where they feel that the new organization has been transformed into an organization with higher status. As Cai argues 'because pursuing higher academic status is a common value and behaviour tendency among academic staff [...] the change of identity to a higher level can increase staff members' value commitment, because the individuals' internal values tend to change toward convergent values and beliefs associated with the new organizational identity.' (2006, 223) Thus, pursuit of academic status seems to be crucial for achieving academic staff integration into the new organization (Cai, 2006).

The introduction of a tenure track system to increase transparency and fairness in terms of academic staff integration was critically valued across studies. A point from Tienari et al. (2016) was that such a system might lead to segregation of staff members, between a small privileged group and a large academic proletariat. Williams et al. (2017) problematized the tenure from two different systems - an urban and a rural campus.

Geographical and physical environment was another theme related to micro-level processes after a merger decision in several studies. According to Cai $(2006,221)$ '[a]cademic staff integration is heavily influenced by geographical separation: teaching and research operate separately, and there are only a couple of meetings where all academics can meet one another each semester. The integration should not be so difficult, because all the 
academic staff members have studied and worked in similar disciplinary areas. The most important factor is that people are geographically separated and have few opportunities to meet face to face. We must work together physically, which is the precondition for integration.' The point that physical distance and cooperation between two units that are geographically separate is challenging, is also made by Puusa and Kekäle (2015), in a study of a Finnish merger.

Studying the importance of facilities and a new accommodation for staff integration, Lawlor (2013) found a positive impact, particularly for staff members 'moving' into the new building that was built for the purposes of the merger.

In sum, integration of academic staff and culture into the merger is closely related to the topic of academic identities. In general, studies addressing academic staff and cultural integration indicate that academic status appears to be crucial for achieving staff integration into the new organization. However, across studies a tenure track system to facilitate transparency and fairness towards academic staff integration was critically assessed, as such a system might lead to staff segregation. Other issues affecting academic staff and cultural integration were those of appropriate facilities and new accommodation for staff, geography and cultural integration.

\section{Staff feelings and emotions}

A large part of the literature addresses the wide range of feelings and emotions that can be related to the merger decision and process. Feelings that were referred to in these studies were those of ambivalence and a wide range of negative emotions, in addition to neutral and positive feelings.

Negative feelings Negative feelings were a theme in several studies.

Investigating the integration of units that differ significantly from traditional universities with regards to tasks, missions, organization and culture in a Danish vertical forced merger, Aagaard et al. (2016) identified a mainly 'negative image of the employee experiences of the mergers and their implications for the current job situation' (p. 49). They relate employees' dissatisfaction to how the merger process was perceived, the current job assessed and how satisfied employees were.

Besides low job satisfaction in relation to a merger, another theme is that of high general skepticism. Aagaard et al. (2016) showed that for many informants the positive outcomes of a merger process were not convincing, and many pointed to a lack of information and degree of involvement. For a vertical forced merger Becker et al. (2004) reported strong feelings related to the work situations, in particular for the incorporated college staff, illustrated by the following quote: 'The relationship between contract appointees and permanent appointees was strained and communication stopped between these two groups while aggression was sometimes experienced (p. 157). At the same time, Becker et al. (2004) found a feeling of guilt reported by informants, related to their colleagues who had not received any appointment at all. At the same time, alienation seemed to be perceived by the incorporated college staff members into the university when they started their new arrangement.

Exploring the vertical forced integration of a national educational research institute within a Grande École in France, Evans (2017) reveal a 'widespread post-merger dissatisfaction, lowered morale, frustration and disillusionment created by people's impeded 
capacity to carry out their work as they wished.' (p. 1699). Particularly themes raised were those of mourning, 'quiet despair' and mental pain ('suffering'), going along with increased stress and workload (Evans, 2017). Emotions of sadness and nostalgia are also reported by Lawlor (2013), who studied the experiences of the post-merger stage. They found that some of the employees showed 'sadness leaving their old location where they had enjoyed many happy and productive years, despite the substandard accommodation [...] (711)'. This emotion seemed to be related to nostalgia 'where the participant appeared to be somewhat mournful for an environment that offered an element of familiarity' (Lawlor, 2013, 711).

Investigating a vertical forced merger in the US, a consolidation of two institutes with different status, Reinke and Evans (2014) found a relation between stress and continuance commitment, which means that employee could be 'caught' in the organization and not able to leave, which would lead to more stress. An increase in stress related to expected research output was also observed among staff members of lower-status institutions that were merged with a higher-status institution (Slade et al., 2016).

Studying the impact of an incorporation of two colleges into one university in South Africa on attitudes, beliefs and perceptions of staff members who were not appointed in posts at the receiving institution Von Westhuizen (2004) identified feelings of isolation and vehement denial, in addition to those of anger and depression.

Similarly, anxiety is another theme identified by several studies. Lawlor (2013), for example, found that staff members, specifically those moving to the new location, were worried about the type of office accommodation and office space they would get at the new campus. Anxiety about changes in working life in the future was also a topic discussed by Evans, which was strongly related to informants' perceptions of 'being kept in the dark' (2017, 1711). At the same time, Evans made the point (2017) that academics might differ from administrative staff, since academics might identify more with their disciplines than their institution. Thus, feelings of anxiety and resistance in mergers of higher education institutions might be stronger among administrative staff compared with academic staff.

Positive feelings To a certain degree, we found also a range of positive feelings across the studies. Becker et al. (2004) referred to positive feelings by college staff during the incorporation into the university towards the students during lectures, even though negative attitudes might unconsciously be visible at the same time. A selected group of staff members who got a position at the new university appeared to become very thankful and expressed enthusiasm and calmness. 'Some remained hopeful throughout, unthreatened by what was happening around them, others experienced a sense of relief and a feeling of affirmation and acceptance.' (167).

Studying a voluntary merger of two similar universities in the UK from a stress and well-being perspective Cartwright et al. (2007) described staff at both organizations as 'relatively healthy in terms of sources and effects of stress at this stage [...] than might have been expected.' (472) It was shown that those who assessed the merger in a positive way experienced less stress, they were more committed to the merger and had a better health status. Positive appraisal of the merger among staff members at the smaller university, so the study authors suggest, might indicate a 'strong identification with a larger and perhaps more prestigious university' (473).

'[S]atisfaction and excitement' among staff members of the merged institutions was reported by Lawlor (2013, 713). Regarding satisfaction, different sub-categories were 
referred to, such as 'satisfaction due to the new geographic location, satisfaction due to their perception of the new building, and satisfaction due to the enhanced academic environment'.

Ambivalent and neutral feelings We also found a pattern of ambiguous feelings in the literature. Exploring feelings among staff members of a merger in France, Evans (2017, 1706), for example, showed a 'general picture of ambivalence', while only a minority of informants provided unambiguous feelings and perceptions. The majority standpoint to the merger was negative, but it was balanced out by an opposite stance ('on the other hand'). Further, Lawlor (2013) referred to both, negative and positive feelings, expressed by staff members. While positive feelings were triggered by the new location, the new building and the improved academic environment, negative feelings were related to a regret by leaving a well-known environment and a feeling of anxiety related to change initiated by the merger. Investigating meanings attributed to a vertical forced merger in Finland by academic staff, similarly, Puusa and Kekäle $(2015,441)$ found various reactions 'from local resistance to constructive criticism and acceptance'.

A rather neutral and pragmatic point of view on the structural changes by staff members was reported in Ylijoki (2014). At the same time, however, she stresses that structural changes at the micro level might mix up with other transformations in higher education and society, which might have an impact on the staffs' perspective. That the social status of the institution might affect staff members' emotions in different ways can be illustrated by the example of a staff member of a high-status Grande École, shown unaffected by the merger (Evans, 2017).

In sum, across the studies a wide range of feelings at the micro level were reported by academic and administrative staff members of higher education institutions, such as negative, ambivalent, positive and neutral feelings. However, across the studies the spectrum between negative and mixed feelings dominates, while positive and neutral feelings appear rather to be related to staff members in privileged positions. Further, there are indications that feelings of anxiety and resistance might be stronger for administrative staff members than academics, as the latter to a stronger degree identify with their discipline.

Teaching and research A couple of studies addressed issues related to core academic activities, like teaching and research, in relation to a merger decision, as perceived by staff members.

For a merger between a research institute and a Grande École, Evans (2017) stressed the issue of service quality provided by the institute. The fear was raised by employees that the research institute and its services would lose their character after the merger. A similar pattern was found by Aagaard et al. (2016), investigating the integration of former governmental research institutes (GRIs) into the university. They found that the majority of the academics 'indicated that the conditions for carrying out consultancy and applied research had been impaired as a result of the mergers.' (p. 49).

Investigating a vertical forced merger in South Africa, Maree and Eiselen (2004) found indications that a dramatic event like a merger between two higher education institutions might hinder the actualization of academics' intellectual potential, and thus, might negatively impact the quality of teaching and research. Pritchard and Williamson 
(2007), who studied a vertical forced merger of two institutions in Northern Ireland retrospectively after 20 years, found that staff complained about a decreasing importance of teaching after a merger, due to an increased focus on research. A higher focus on research was also reported by Slade et al. (2016), who found that the lower-status university members spend more time on research, which was associated with more stress.

However, studying mergers in Finland, Ursin and Aittola (2019) identified an improvement in the status of teaching as an important topic and the hope raised by informants to retain the relationship between teaching and research. The importance of improving the quality of teaching and learning was mentioned - in alignment with the principles of the Bologna process (see, e.g., Kehm, 2010). Informants stressed that the merging of universities, with their individual educational profiles, could provide highly valued study internationally.

Further, innovative models for teaching and learning emerged as a topic by Ursin and Aittola (2019) who suggest that merged universities might 'organize more diversified study programmes and broaden the range of subjects [...] to encourage students to choose different subjects $[\ldots]$ leading to novel subject combinations [...].' Additionally, this might imply a more interactive and student-centered teaching.

Another topic was that of 'rationalization' to distinguish the profiles of the merging universities and to improve their core activities. As the profiles are built on the universities' prevailing strengths, the informants anticipated that the new universities after the merger could play a more powerful role in the (inter)national educational market (Ursin \& Aittola, 2019).

In sum, the studies in our sample that addressed a change in teaching and research quality in relation to a merger found mixed results, indicating a decrease in the quality - particularly in teaching - and an improvement of the quality of teaching and research in alignment with the principles of the Bologna process. Further topics are innovation in teaching and learning and a changing balance between teaching and research.

\section{Discussion and conclusion}

Concerning mergers of different types of higher education institutions, we asked if the type of higher education merger affect micro-level processes? We assumed that mergers impact phenomena at the micro level, such as changes in academic identity, academic staff integration, a variety of staff emotions and the core academic activities, teaching and research. Further, we assumed that micro-level processes might differ for different staff groups and that the national context, including educational policies at the macro level, in addition to the type of merger at the meso level, affects the micro level. Across the studies included, we discuss here some points of importance for micro-level processes before, during and after a merger decision of higher education institutions.

Time appears to be a crucial element for micro-level processes and post-merger integration. That it is time-consuming to build a new culture and identity for the merged higher education institution might be underestimated. Several studies, among them three conducted in Finland, point to the importance of time to reach the original goals of the merger - higher quality of research and education - in addition to a more efficient institution (Leslie et al., 2018; Puusa \& Kekäle, 2015; Tienari et al., 2016; Ursin \& Aittola, 2019). To investigate the importance of time for micro-level processes and post-merger integration, we need more studies with a longitudinal research design. 
Sensitivity to different cultures of merging institutions Other studies stress the importance of sensitivity to different cultures and identities of the merging institutions, which for instance might be dependent on the relation between research and teaching and institutional status (Cai, 2006; Ursin \& Aittola, 2019). Further, studies might further explore how the relation between research and teaching and institutional status on the one side, and sensitivity to different cultures and identities of the merging institutions on the other side, impact micro-level processes over time and in different national contexts.

\section{Status differences according to institutions and staff groups was another point across}

studies How status differences of institutions affect the micro level was addressed by Ribando et al. (2017) and Gleibs et al. (2013). Findings suggest that staff from lower-status institutions experience the merger more negatively than staff from higher-status institutions, as the culture of the latter will dominate the culture of the merged institutions. This means staff from lower-status institutions feel more stress and pressure to live up to new standards, for example in terms of research than those from higher-status institutions. Further, findings indicate that mergers affect groups of staff in a different way. Mergers seem to affect high-status groups (e.g., academics with permanent contracts) less negatively compared with lower-status groups like academics with non-permanent contracts, and administrative staff. There are indications that high-status groups perceive mergers rather in a positive way. Further studies might investigate within-group differences for high-status groups and lower-status groups, for example in terms of gender and discipline.

Meso level We assumed that the type of merger at the meso level affects micro-level processes. Voluntary mergers with a long cooperation between institutions (academics) appear to neutralize negative impacts of merger processes, such as feelings of anger and a threatening of one's academic identity, on staff, who might continue to work as usual. In contrast, forced mergers tend to reinforce such effects, leading to negative emotions and a diminished self-image and identity among academic staff. This review has focused on the merger categories voluntary vs. forced and horizontal vs. vertical and number of institutions involved in a merger. Further research might investigate the relationship between different merger categories and micro-level processes.

Macro level Our review identified studies from different countries which have experienced major changes in their higher education institution landscape over recent decades, changes mainly due to political reforms. The context of these reforms will naturally differ across countries, and thus might have an indirect impact on merger processes at the micro level. Here we found that studies conducted in South Africa with a long history of apartheid mainly address emotional and perceptual perspectives. In contrast, studies conducted in Finland mainly address issues of academic identities embedded in the larger context of an increasing fragmentation and heterogeneity of the academic profession (see, also, Ylijoki \& Ursin, 2013). This pattern might be related to a trend of globalization and new dynamics within higher education institutions and collaborations with external stakeholders (see, e.g., Välimaa, 2004). Further research might take an international comparative perspective by studying micro-level processes in merger institutions in light of political reforms and national contexts.

Another of studies addressing the cultural perspectives were conducted in the United States, characterized by a highly fragmented higher education landscape with different 
types of universities (Anthony, n.n.). Across studies, status and cultural differences between institutions seemed to be problematic issues for post-merger integration.

\section{Limitations and implications for further research}

A strength of this review is that it applies systematic procedures for literature search, study selection, coding and extraction of information and analysis, which allow transparency and replicability. Even though applying procedures of the systematic review methodology, we did not appraise the quality of each study by using standardized checklists, a regular procedure in regular systematic reviews, which is a limitation of our review. Furthermore, our literature search was limited to two electronic databases and Google scholar and a selection of additional sources. At the same time, this review synthesizes mainly qualitative studies in a configurative manner and informed by the logics of qualitative research. Of 21 included studies six are conducted in Nordic countries, namely Finland (five studies) and Denmark (one study) which might have introduced a certain bias in the analysis in favor of these contexts.

In the following, we provide some implications for further research. Our review has found that time is an important aspect for understanding merger processes and outcomes on the micro level, which requires a longitudinal research design (see also Graebner et al., 2017). Only few studies have investigated the impact of mergers over time (e.g., Pritchard and Williamson 2007). One example is Gleibs et al. (2010), who investigated perceptions of the merger by students, using a pre-post design. This study was, however, not included in our review, as it addressed exclusively students and not staff. Puusa and Kekäle (2015) applied a longitudinal case study design to explore meanings and interpretations regarding a merger by academic staff over three years in Finland. However, their conclusion that 'the integration process between the campuses' still is not finalized indicates that we need more research with a longitudinal perspective to study merger impacts on micro-level processes (see, Pritchard and Williamson 2007).

We argue that micro-level processes impact teaching and research activities (see also: Harman \& Harman, 2003). Relatively few studies, however, investigate the impact of a merger on teaching and research activities (Safavi \& Håkanson, 2018; Slade et al., 2016; on meso level, Liu et al., 2018) and their quality. Studying consequences of a merger for teaching and research is highly complex and requires a longer time frame and the involvement of a student perspective, in addition to an academic staff perspective and an investigation of more quantitative indicators. Further studies might use a longitudinal design to investigate changes over time, from different angles and for different staff groups and students.

Finally, our review has found that mergers in higher education are embedded in different national contexts. Thus, further studies might further explore country differences related to micro-level processes by applying a comparative design. In a study of highperforming universities in Europe, Ripoll-Soler and de-Miguel-Molina (2019) show that different context factors at local, national and international level impact post-merger processes. Despite these limitations, our review, together with longitudinal studies, might inform the planning of merger processes in relation to anticipated reactions at the micro level. 
Open Access This article is licensed under a Creative Commons Attribution 4.0 International License, which permits use, sharing, adaptation, distribution and reproduction in any medium or format, as long as you give appropriate credit to the original author(s) and the source, provide a link to the Creative Commons licence, and indicate if changes were made. The images or other third party material in this article are included in the article's Creative Commons licence, unless indicated otherwise in a credit line to the material. If material is not included in the article's Creative Commons licence and your intended use is not permitted by statutory regulation or exceeds the permitted use, you will need to obtain permission directly from the copyright holder. To view a copy of this licence, visit http://creativecommons.org/licenses/by/4.0/.

\section{References}

Aagaard, K., Hansen, H. F., \& Rasmussen, J. G. (2016). Mergers between governmental research institutes and Universities in the Danish HE sector. European Journal of Higher Education, 6(1), 41-55.

Anthony, A. (n.n.). A Review of the U.S. Higher Education System: Its Structure, Funding, Quality and the Future. [unpublished manuscript].

Becher, T., \& Trowler, P. (1989). Academic Tribes and Territories. Society for Research into Higher Education Open University Press.

Becker, L. R., Beukes, L. D., Botha, A., Botha, A. C., Botha, J. J., Botha, M., ... Vorster, A. (2004). The impact of university incorporation on college lecturers. Higher Education, 48(2), 153-172.

Boling, J. R., Mayo, D. T., \& Helms, M. M. (2017). Complementarity merger as a driver of change and growth in higher education. Journal of Organizational Change Management, 30(1), 27-42.

Cai, Y. (2006). A case study of academic staff integration in a post-merger Chinese university. Tertiary Education Management, 12(3), 215-226.

Cartwright, S., Tytherleigh, M., \& Robertson, S. (2007). Are mergers always stressful? Some evidence from the higher education sector. European Journal of Work and Organizational Psychology, 16(4), 456-478.

Damşa, C., de Lange, T., Elken, M., Esterhazy, R., Fossland, T., Frølich, N., et al. (2015). Quality in Norwegian Higher Education: A review of research on aspects affecting student learning. NIFU-rapport;2015:24. NIFU.

Dasborough, M., Lamb, P., \& Suseno, Y. (2015). Understanding emotions in higher education change management. Journal of Organizational Change Management, 28(4), 579-590.

Elliot, J. (2005). Merging right : questions of access and merit in South African higher education reform, 1994-2002. Perspectives in Education, 23(1), 69-76.

Evans, L. (2017). The worst of times? A tale of two higher education institutions in France: Their merger and its impact on staff working lives. Studies in Higher Education, 42(9), 1699-1717.

Frølich, N., Trondal, J., Caspersen, J., \& Reymert, I. (2016). Managing mergers-governancing institutional integration. Tertiary Education, 22(3), 231-248.

Gleibs, I. H., Noack, P., \& Mummendey, A. (2010). We are still better than them: A longitudinal field study of ingroup favouritism during a merger. European Journal of Social Psychology, 40(5), 819-836.

Gleibs, I. H., Täuber, S., Viki, G. T., \& Giessner, S. R. (2013). When What We Get Is Not What We Want. Social Psychology, 44(3), 177-190.

Gornitzka, А. (1999). Governmental policies and organisational change in higher education. Higher Education, 38(1), 5-31.

Graebner, M. E., Heimeriks, K. H., Huy, Q. N., \& Vaara, E. (2017). The Process of Postmerger Integration: A Review and Agenda for Future Research. Academy of Management Annals, 11(1), 1-32.

Harman, K. (1989). Culture and Conflict in Academic Organisation: Symbolic Aspects of University Worlds. Journal of Educational Administration, 27(3).

Harman, K. (2002). Merging divergent campus cultures into coherent educational communities: Challenges for higher education leaders. Higher Education, 44(1), 91-114.

Harman, G., \& Harman, K. (2003). Institutional mergers in higher education: Lessons from international experience. Tertiary Education and Management, 9(1), 29-44.

Harman, G., \& Harman, K. (2008). Strategic mergers of strong institutions to enhance competitive advantage. Higher Education Policy, 21(1), 99-121.

Johnes, J., \& Tsionas, M. G. (2019). Dynamics of Inefficiency and Merger in English Higher Education From 1996/97 to 2008/9: A Comparison of Pre-Merging, Post-Merging and Non-Merging Universities Using Bayesian Methods. Manchester School, 87(3), 297-323. 
Kehm, B. M. (2010). Quality in European Higher Education: The Influence of the Bologna Process. Change: the Magazine of Higher Learning, 42(3), 40-46.

Kyvik, S. (2004). Structural changes in higher education systems in Western Europe. Higher Education in Europe, 29(3), 393-409.

Lawlor, J. (2013). Employee perspectives on the post-integration stage of a micro-merger. Personnel Review, 42(6), 704-723.

Leslie, H., Abu-Rahma, A., \& Jaleel, B. (2018). In retrospect: A case of merger in higher education. International Journal of Educational Management, 32(3), 382-395.

Liu, Q., Patton, D., \& Kenney, M. (2018). Do university mergers create academic synergy? Evidence from China and the Nordic Countries. Research Policy, 47(1), 98-107.

Maree, J. G., \& Eiselen, R. J. (2004). The emotional intelligence profile of academics in a merger setting. Education and Urban Society, 36(4), 482-504.

Marginson, S. (1997). Steering from a distance: Power relations in Australian higher education. Higher Education, 34(1), 63-80.

Pritchard, R. M. O., \& Williamson, A. (2007). Long-term human outcomes of a "Shotgun" marriage in higher education. Higher Education Management and Policy, 20(1). https://doi.org/10.1787/ hemp-v20-art3-en.

Puusa, A., \& Kekäle, J. (2015). Feelings over facts - a university merger brings organisational identity to the forefront. Journal of Higher Education Policy and Management, 37(4), 432-446.

Reinke, S. J., \& Evans, L. (2014). Change happens: Assessing the initial impact of a university consolidation on faculty. Public Personnel Management, 1-21.

Ribando, S. J., Slade, C. P., \& Fortner, C. K. (2017). Once More into the Breach: Examining the Human Capital Impact of a University Consolidation over Time. Innovative Higher Education, 42(5-6), 521-535.

Richards, L. (2009). Handling Qualitative Data: A Practical Guide. L. Sage.

Ripoll-Soler, C., \& de M, M. M. (2019). Higher education mergers in Europe: a comparative study of the post-merger phase. Tertiary Education and Management, 25(3), 255-271.

Robson, C., \& McCartan, K. (Eds.). (2011). Real World Research. Fourth Edition. Wiley.

Rowley, G. (1997). Mergers in higher education: A strategic analysis. Higher Education Quarterly, 51(3), 251-263.

Safavi, M., \& Håkanson, L. (2018). Advancing theory on knowledge governance in universities: A case study of a higher education merger. Studies in Higher Education, 43(3), 500-523.

Saini, M. \& Shlonsky, A. (2012). Systematic synthesis of qualitative research. Oxford University Press.

Skodvin, O. J. (1999). Mergers in higher education-success or failure? Tertiary Education Management, 5(1), 65-80.

Slade, C. P., Ribando, S. J., \& Fortner, C. K. (2016). Faculty research following merger: A job stress and social identity theory perspective. Scientometrics, 107(1), 71-89.

Thorne, S., Jensen, L., Kearney, M. H., Noblit, G., \& Sandelowski, M. (2004). Qualitative Metasynthesis: Reflections on Methodological Orientation and Ideological Agenda. Qualitative Health Research, 14(10), 1342-1365.

Tienari, J., Aula, H.-M., \& Aarrevaara, T. (2016). Built to be excellent? The Aalto University merger in Finland. European Journal of Higher Education, 6(1), 25-40.

Ursin, J. (2017). Tranforming Finnish Higher Education: Institutional Mergers and Conflicting Academic Identities. Rie-Revista De Investigacion Educativa, 35(2), 307-316.

Ursin, J., \& Aittola, H. (2019). 'It's Not Like Everything Changes Just With a Click on New Year's Eve': Perceptions on Educational Issues of University Mergers in Finland. Higher Education Policy.

Välimaa, J. (2004). Nationalisation, Localisation and Globalisation in Finnish Higher Education. Higher Education, 48, 27-54.

Van der Westhuizen, C. N. (2004). The games institutions play - or the impact of university incorporation on the attitudes, beliefs and perceptions of college lecturers : Perspectives on higher education. South African Journal of Higher Education, 18(1), 153-164.

van Vuuren, M., Beelen, P., \& de Jong, M. D. T. (2010). Speaking of dominance, status differences, and identification: Making sense of a merger. Journal of Occupational and Organizational Psychology, 83(3), 627-643.

Walsh, D. \& Downe, S. (2005). Meta-synthesis method for qualitative research: A literature review. Journal of Advanced Nursing, 50(2), 204-211.

Williams, H., Feldman, L., \& Conners, S. (2017). Impact of an Institutional Merger on Four Internal Stakeholder Groups of a College of Business? Journal of Academic Administration in Higher Education, 13(2), 21-30. 
Yang, R. (2000). Tensions between the global and the local: A comparative illustration of the reorganisation of China's higher education in the 1950s and 1990s. Higher Education, 39(3), 319-337.

Ylijoki, O.-H. (2014). University under structural reform: A micro-level perspective. Minerva, 52(1), 55-75.

Ylijoki, O.-H., \& Ursin, J. (2013). The construction of academic identity in the changes of Finnish higher education. Studies in Higher Education, 38(8), 1135-1149.

Publisher's note Springer Nature remains neutral with regard to jurisdictional claims in published maps and institutional affiliations. 